\title{
An Ultrastructural Study of Precleavage Mitosis in the Myxomycete Arcyria cinerea
}

\author{
By C. W. MIMS* \\ The Cell Research Institute and Department of Botany, University of Texas, \\ Austin, Texas, 78712, U.S.A.
}

(Accepted for publication 3 January I97I)

\begin{abstract}
SUMMARY
The precleavage mitotic division in Arcyria cinerea was intranuclear and involved no centrioles. The division was nearly synchronous throughout the sporangium although nuclei in the upper portion of the sporangium usually began to divide first. At metaphase nuclei were roughly spherical. Intranuclear spindle fibres were visible and appeared to terminate near the inner surface of the nuclear envelope. By telophase the nuclei were very elongated In late telophase the nuclear envelope broke first in the interzonal region and then at the poles. The reconstitution of the nuclear envelope appeared to involve remnants of the original envelope as well as small vesicular elements resembling short segments of rough endoplasmic reticulum. The chromosomal spindle fibres, as well as some interzonal fibres, usually persisted until the nuclear envelope was completely reconstituted around a daughter nucleus. The division was completed by the time spore cleavage began in the sporangium.
\end{abstract}

\section{INTRODUCTION}

Recently, considerable attention has been focused upon nuclear behaviour during sporulation in the Mxyomycetes because of the controversy over the life-cycle of these organisms (Gray \& Alexopoulos, I968). From electron-microscope studies (Aldrich, 1967; Aldrich \& Mims, I970; Aldrich \& Carroll, I97I), it now appears that meiosis occurs in myxomycete spores some $\mathrm{I} 2$ to $24 \mathrm{~h}$ after cleavage rather than in the precleavage sporangium. The ultrastructural details of the mitotic division preceding spore cleavage have, however, received little attention. Particularly lacking is information on the terminal stages of the division. Schuster (1964) has shown some stages of the division in Didymium nigripes (Link) Fr., but only Aldrich (1969), working with Physarum flavicomum Berk., has described the division in detail. Physarum flavicomum and D. nigripes belong to the Physarales. In this paper the ultrastructural details of the precleavage mitotic division in Arcyria cinerea (Bull) Pers., one of the Trichiales, are described.

\section{METHODS}

Methods for growth of an isolate of Arcyria cinerea (UTMC I 204) and for the preparation of sporangia in various stages of development were described previously (Mims, I969). Sections were cut with a diamond knife on a Porter-Blum MT-I ultramicrotome, stained with lead citrate and examined with an EMU-3F RCA electron microscope.

Observations. Interphase nuclei in young precleavage sporangia of Arcyria cinerea were usually roughly spherical and approximately $3 \mu \mathrm{m}$ in diameter (Fig. I). Each was surrounded by a typical nuclear envelope interrupted by a number of pores. The chromatin appeared to

* Present address: Department of Biology, Stephen F. Austin State University, Nacogdoches, Texas, 7596i, U.S. A. 


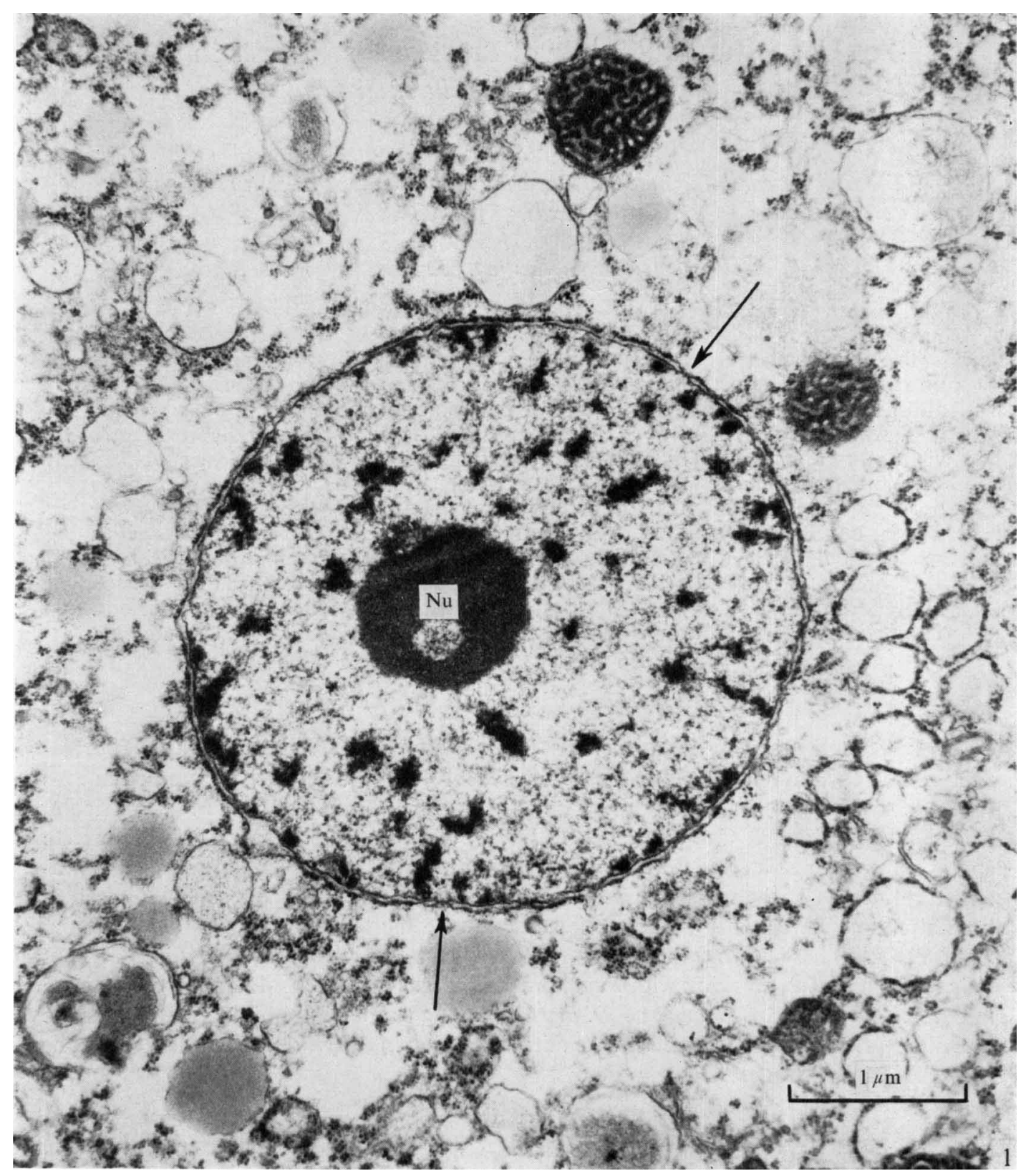

Fig. 1. Interphase nucleus. Note nucleolus $(\mathrm{Nu})$ and nuclear pores at the arrows.

be randomly dispersed throughout the nucleus and each nucleus contained a prominent nucleolus (Fig. I).

The first indication of the onset of mitosis in the sporangium was the condensation of nuclear material into chromosomes and the appearance of intranuclear spindle fibres (Fig. 2). Although still visible in Fig. 2, the nucleolus disappeared during the latter stages of prophase. Division was nearly synchronous (Fig. 3) throughout the sporangium, although 


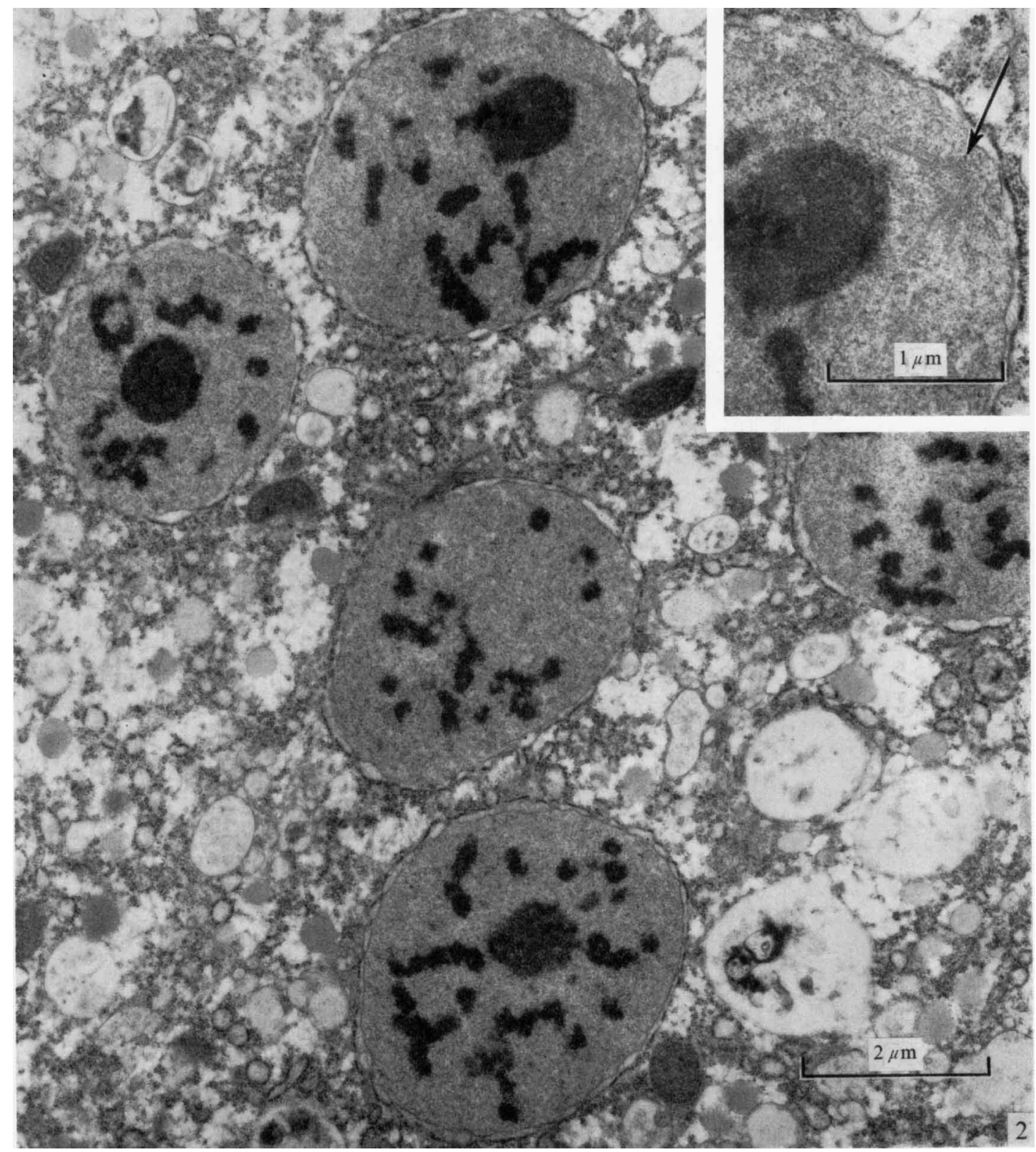

Fig. 2. Prophase nuclei. Chromatin has begun to condense into chromosomes. Nucleoli are still present. Higher magnification of a portion of one of the prophase nuclei is shown in the insert at upper right. A portion of the spindle apparatus is just visible.

nuclei in the upper portion of the elongated sporangium usually began to divide first. The division was intranuclear and involved no centrioles (Fig. 3, 4). Spindle fibres terminated at the poles near the inner surface of the nuclear envelope, but apparently did not contact the envelope (Fig. 3). Metaphase nuclei were at first still roughly spherical (Fig. 3), but as the division continued they elongated. By telophase they were extremely elongated (Fig. 4). 

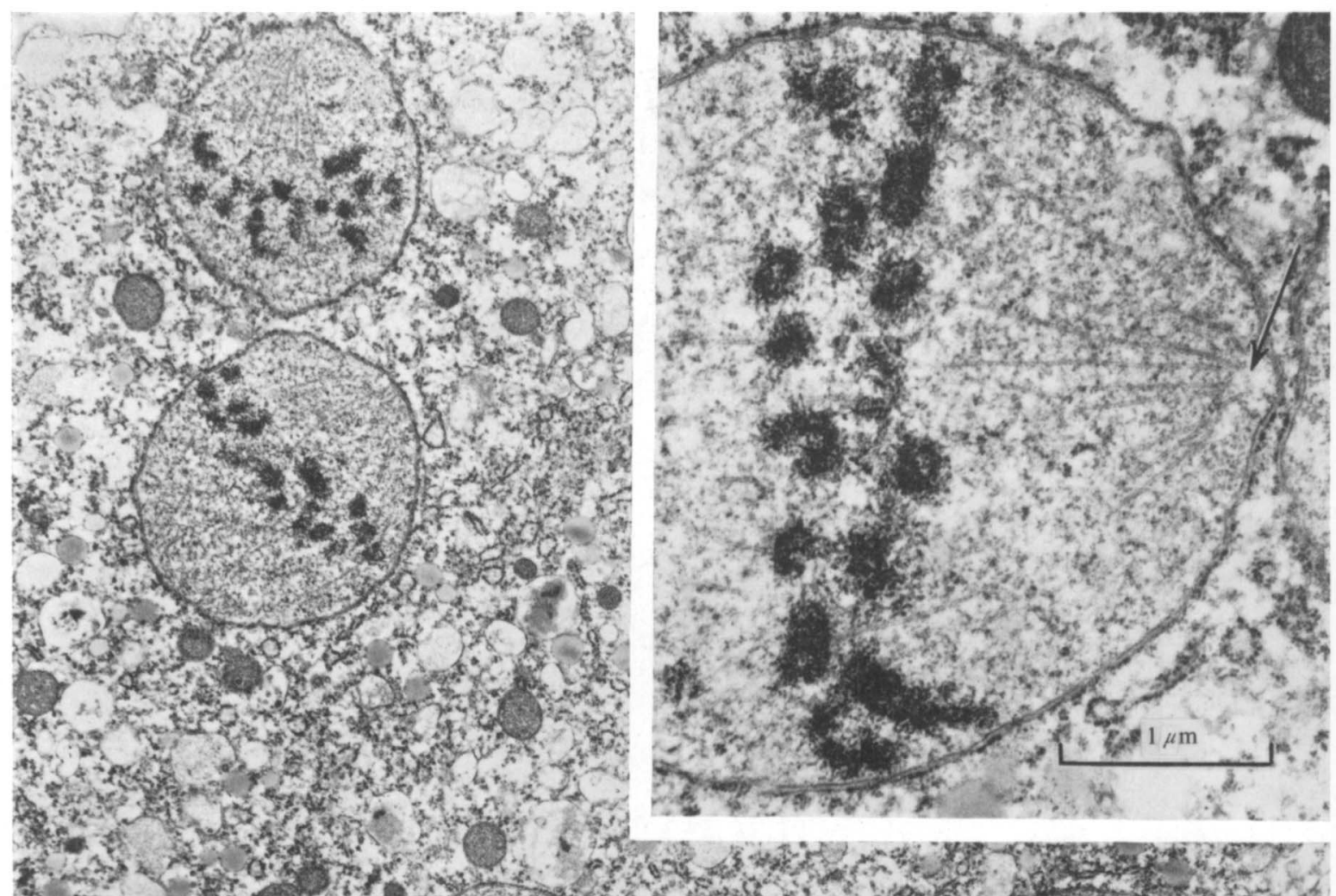

28

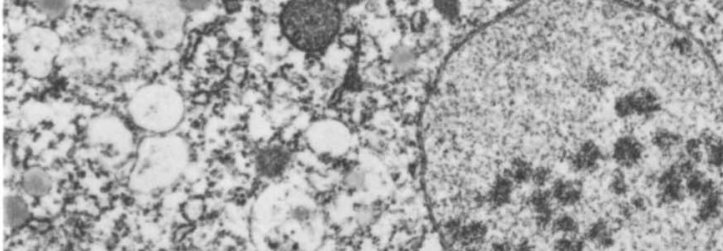

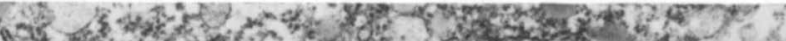
of

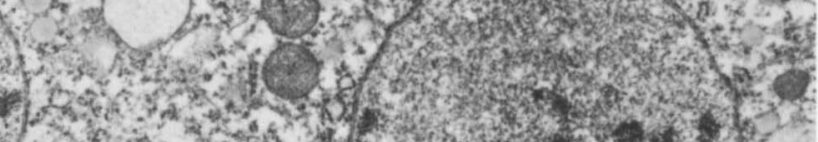

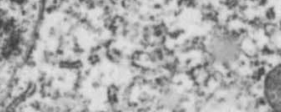

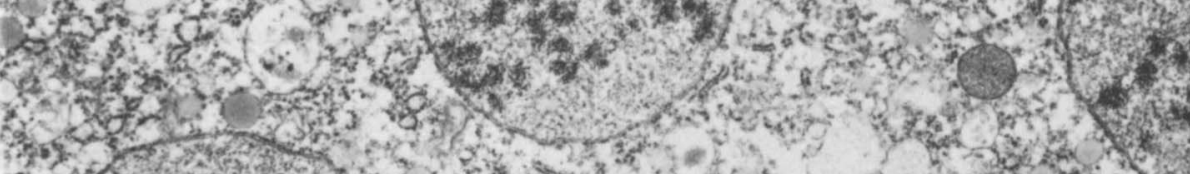

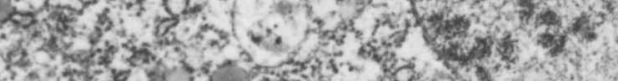
C.

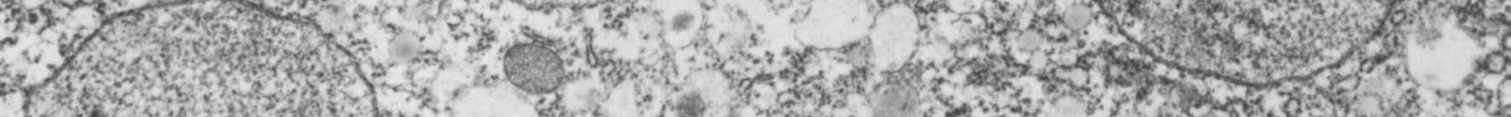

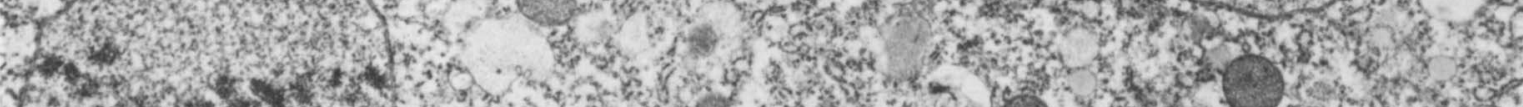

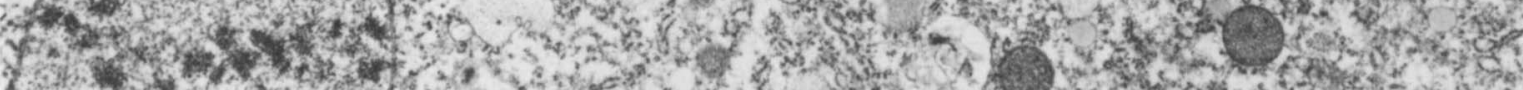

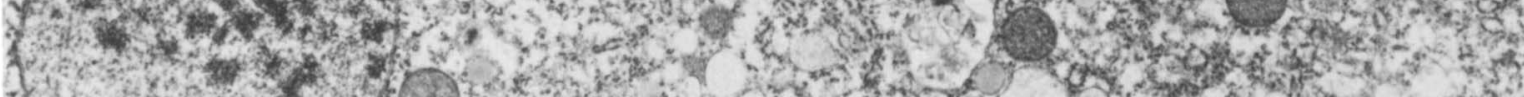

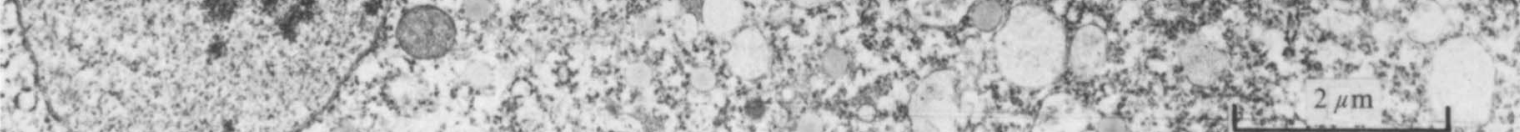

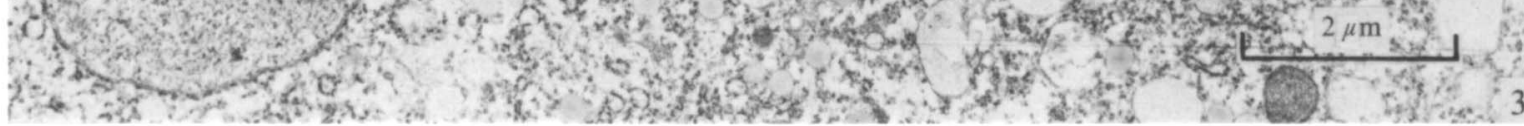

Fig. 3. Section showing a number of metaphase nuclei. Higher magnification of a portion of a metaphase nucleus is shown in the insert at upper right. Spindle fibres (at arrow) appear to terminate near the inner surface of the nuclear envelope. 


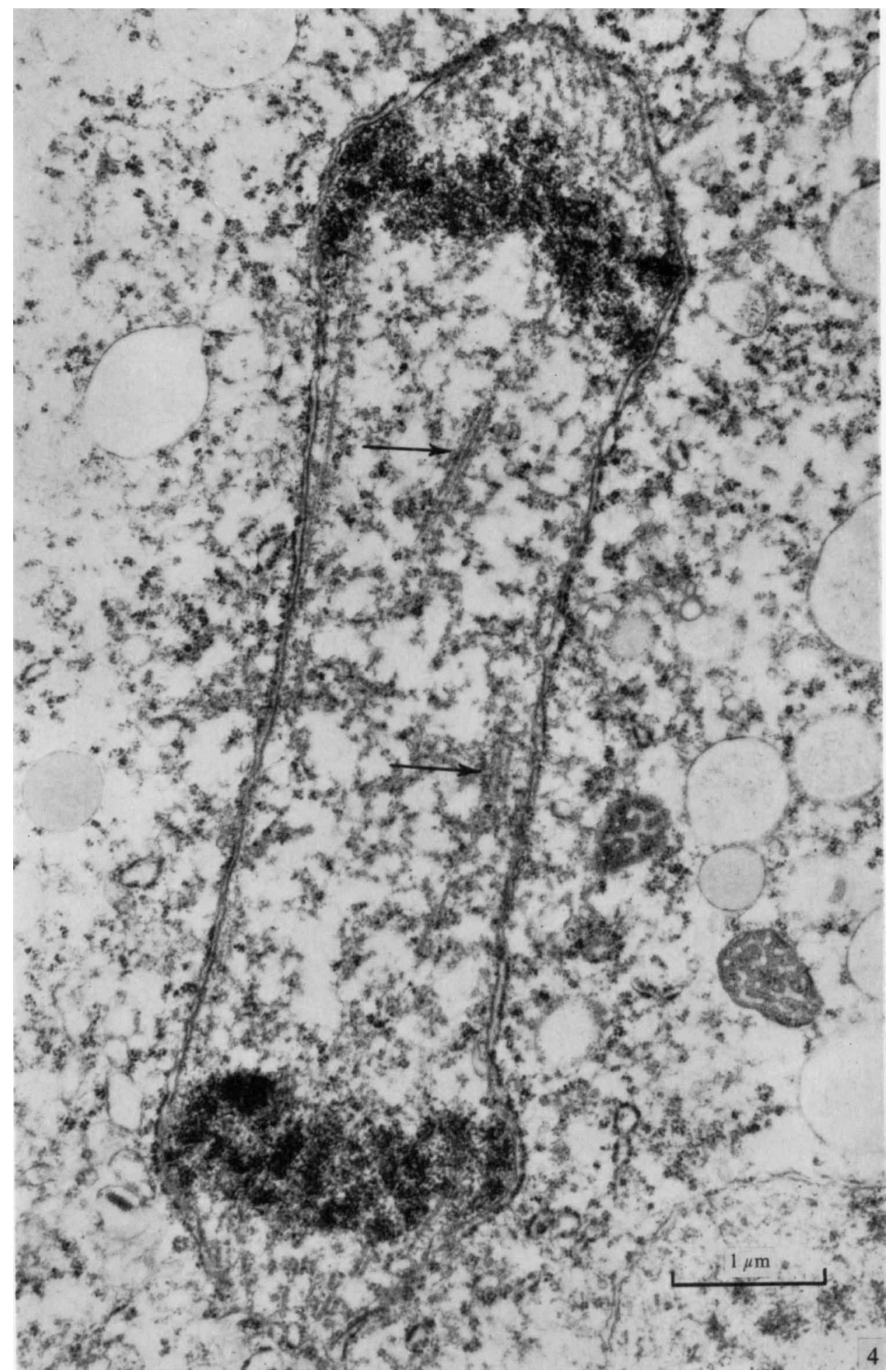

Fig. 4. Greatly elongated telophase nucleus. Note persistence of the nuclear envelope. Also note the interzonal spindle fibres at the arrows. 

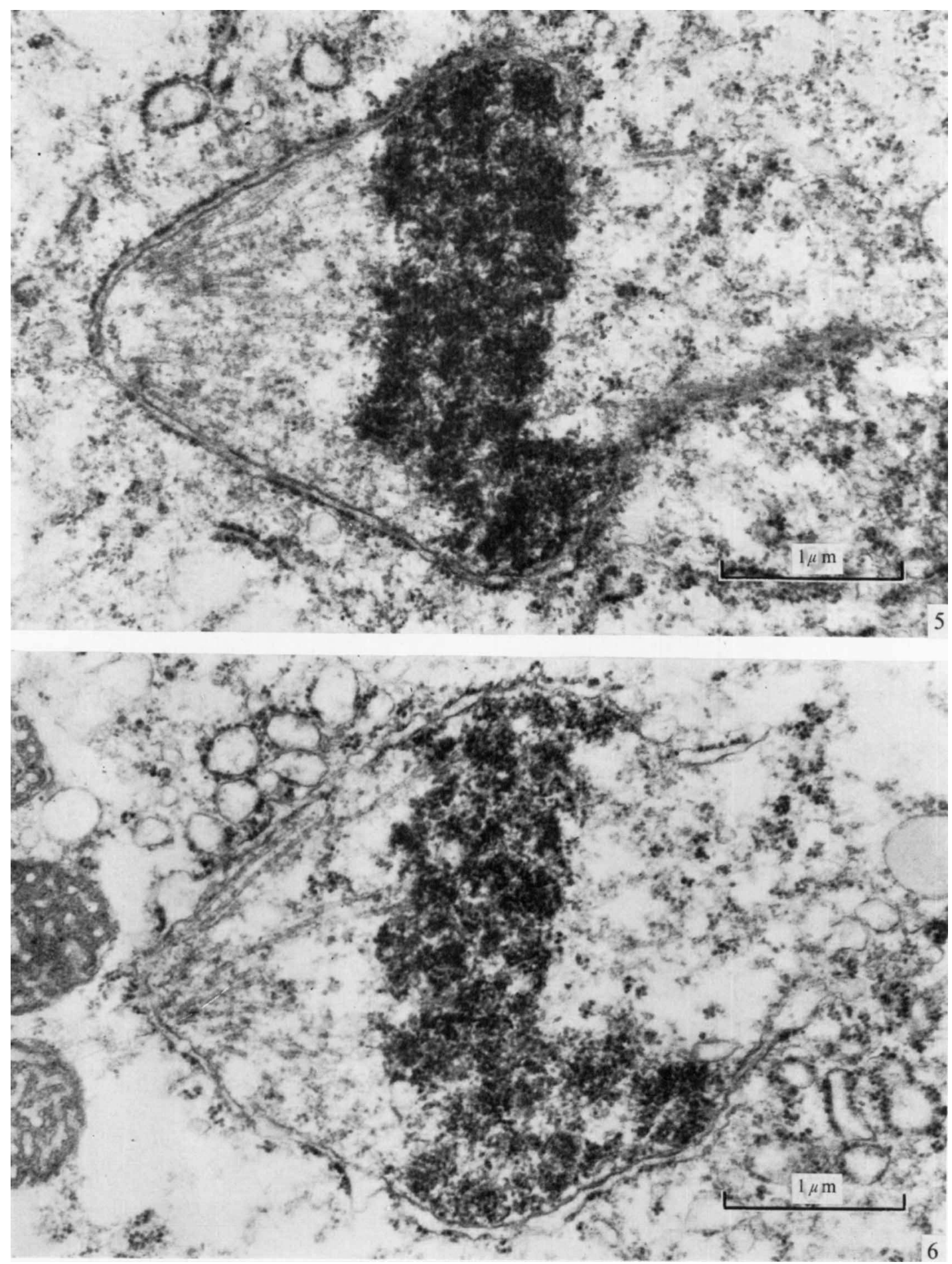

Fig. 5, 6. Portions of telophase nuclei shortly after the rupture of the nuclear envelope in the interzonal region. Note the continuity of the nuclear envelope in the polar region. Chromosomal spindle fibres are still visible. 

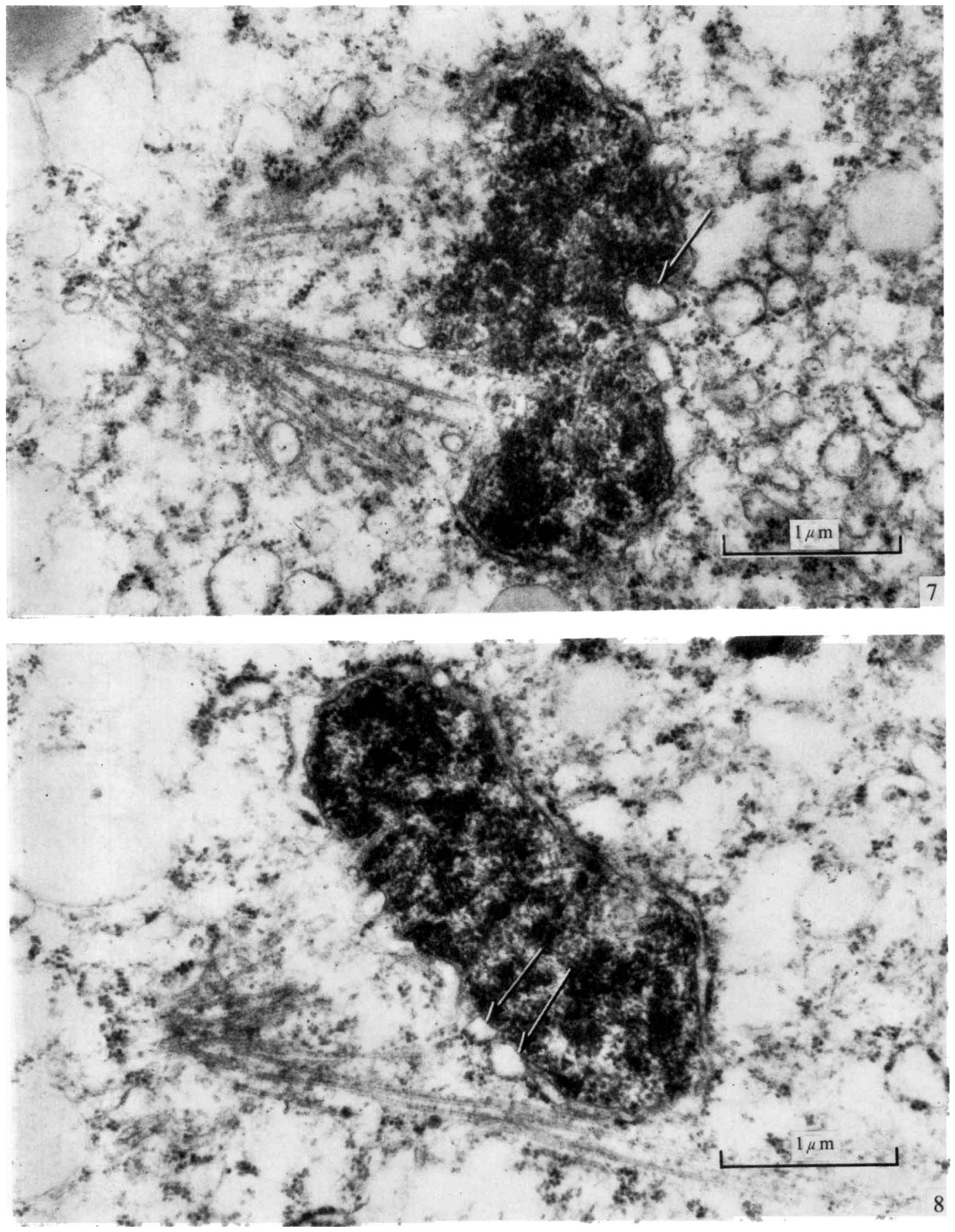

Fig. 7. Young daughter nucleus shortly after the rupture of the nuclear envelope at the pole. The nuclear envelope has begun to reform on the interzonal side of the nucleus. Note vesicular element (at arrow) which appears to be involved in the formation of the nuclear envelope. Also note the chromosomal spindle fibres.

Fig. 8. Young daughter nucleus. Nuclear envelope has been almost completely reconstituted. Note small vesicular elements (at arrows) which appear to be involved in the formation of the nuclear envelope. 

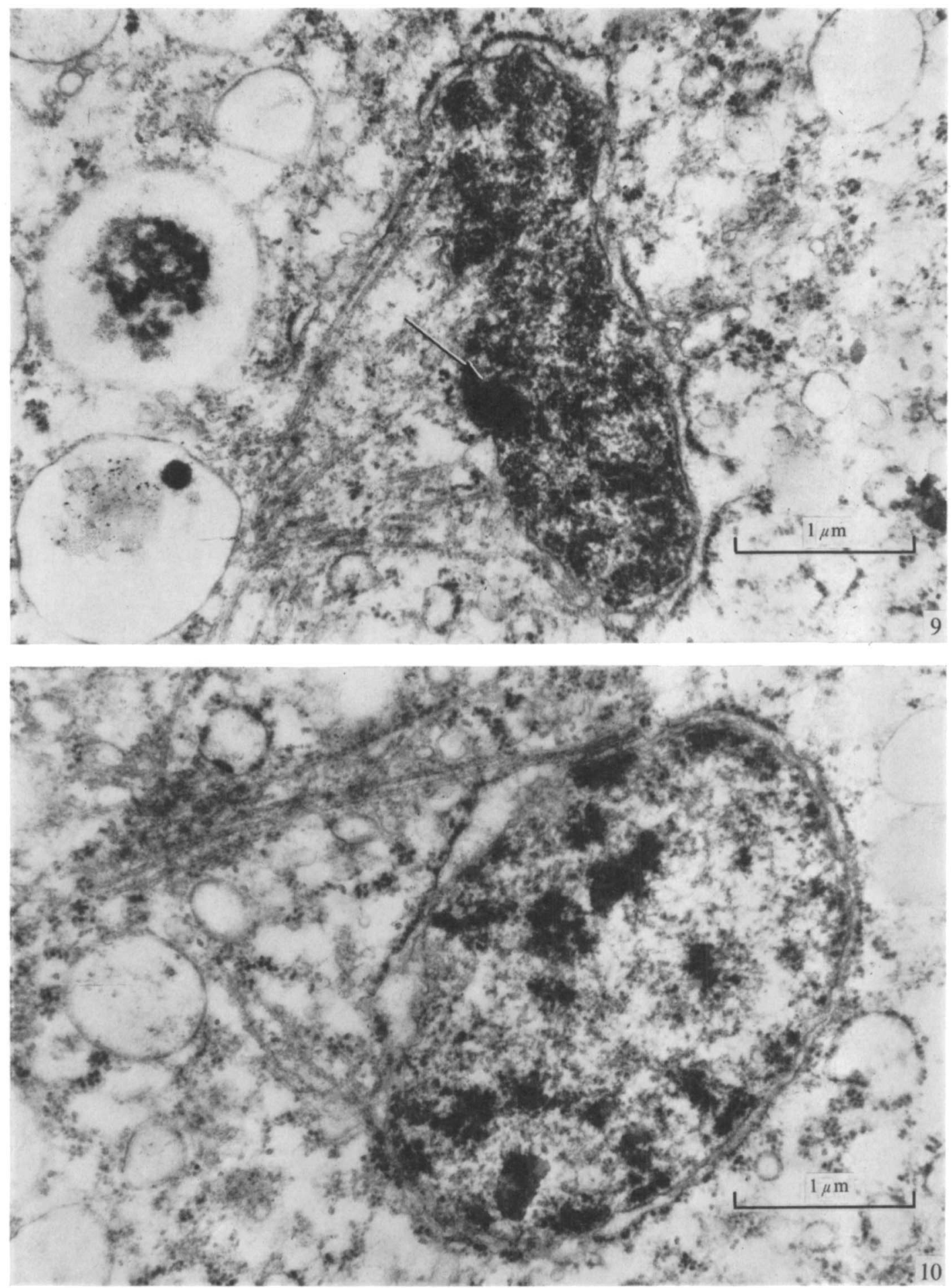

Fig. 9. Young daughter nucleus in which the nucleolus (at arrow) is just visible.

Fig. 10. Daughter nucleus in which the nuclear membrane has been completely reconstituted. Note remnants of the spindle apparatus. 
Interzonal spindle fibres were still visible in telophase nuclei (Fig. 4), but whether or not they were continuous from pole to pole at this stage is not known. The nuclear envelope remained intact until very late in telophase, but eventually broke in the interzonal regions and finally in the polar regions(Fig. 5 to 7 ). Most of the interzonal fibres disappeared shortly after the nuclear envelope had broken, but the chromosomal fibres usually persisted for a much longer period (Fig. 7 to 10 ). The spindle fibres appeared to terminate as a group directly in the cytoplasm (Fig. 7 to 9).

The nuclear envelope of a daughter nucleus was first reconstituted on the interzonal side of the nucleus (Fig. 7). It appeared that remnants of the original envelope closed around the daughter nuclei although a number of small vesicular elements resembling fragments of rough endoplasmic reticulum also appeared to be incorporated into the new envelope (Fig. $7,8)$. It is possible, however, that these vesicular elements were also remnants of the original nuclear envelope. In any event, the nuclear envelope was almost completely reorganized before the spindle fibres were released into the cytoplasm (Fig. 8 to Io). Remnants of the spindle apparatus persisted for some time after completion of the division and were usually visible in the cytoplasm very near the daughter nuclei (Fig. Io). The daughter nuclei were at first flattened (Fig. 9), but soon enlarged and became more nearly spherical (Fig. 10). The nucleolus became visible again during reconstitution of the nuclear envelope (Fig. 9). The mitotic division was completed before the onset of spore cleavage.

\section{DISCUSSION}

Precleavage nuclear division in Arcyria cinerea was very similar to division in Physarum flavicomum (Aldrich, 1969). The division appeared to be a normal mitotic division similar to plasmodial mitosis. The fine structure of mitotic divisions in myxomycete plasmodia have been studied by McManus \& Roth (1968), Guttes, Guttes \& Ellis (1968) and Ryser (1970). McManus \& Roth (1968) studied Clastoderma debaryanum A. Blytl., one of the Stemonitales, but unfortunately were able to find only metaphase figures. Guttes et al. (1968) and Ryser (1970), on the other hand, were able to demonstrate nuclei in various stages of division in $P$. polycephalum Schw. While Guttes et al. (1968) failed to find interzonal fibres in the anaphase spindle, they are clearly visible in Ryser's (1970) micrographs. Guttes et al. (I968) also noted 'clumps of dense amorphous material' in the interzonal region at anaphase, but such material is not visible in Ryser's (1970) material. Finally, while Guttes et al. (1968) reported that the 'restoration of an intact nuclear membrane begins on the side of the chromosomal plate which faces the former spindle pole', Ryser (1970) found that the nuclear envelope was reformed first on the interzonal side of the daughter nucleus.

My observations on Arcyria cinerea, as well as those of Aldrich (1969) on Physarum flavicomum, are more closely in agreement with Ryser's (1970) findings than with those of Guttes et al. (1968). In A. cinerea and P. flavicomum, interzonal spindle fibres are present at anaphase and the clumps of amorphous material described by Guttes et al. (I968) are absent. The reconstitution of the nuclear envelope in $A$. cinerea appeared to be similar to that described by Ryser (1970), and although Aldrich (1969) did not comment on this subject in the precleavage division, he did find that the envelope was reconstituted first on the interzonal side after myxamoebal mitosis in P. flavicomum. It should be pointed out, however, that myxamoebal mitosis differs from plasmodial and precleavage mitosis since it involves centrioles and is not intranuclear.

My observations concerning the rupture of the nuclear envelope during late telophase in Arcyria cinerea differ from those of Aldrich (1969), Guttes et al. (1968) and Ryser (1970) on 
Physarum. In $A$. cinerea the envelope broke first in the interzonal region and then in the polar regions. In both Physarum polycephalum (Guttes et al. 1968; Ryser, 1970) and $P$. flavicomum (Aldrich, 1969), the reverse is true. I also have observed the sequence described in Physarum in two species of Stemonitis (C. W. Mims, unpublished data) and am therefore uncertain whether the sequence in $A$. cinerea is unique or possibly abnormal.

In Arcyria cinerea, as well as in Physarum polycephalum (Guttes et al. 1968; Ryser, 1970) and $P$. flavicomum (Aldrich, 1969), the nuclear envelope of a daughter nucleus appears to originate, at least in part, from remnants of the original envelope. Aldrich (1969) states that in $P$. flavicomum 'at late telophase the nuclear envelope closes around the daughter nuclei as they round up, with continuous spindle fibres and nuclear envelope fragments persisting in the interzonal region'. Similarly, in $P$. polycephalum Ryser (1970) found that 'vesicles covered with ribosomes accumulate in the resulting membrane-free areas, and contribute, together with portions of the old nuclear envelope, to the building of the new nuclear envelope'. As mentioned previously, similar vesicles were also noted in this study.

In conclusion, two points deserve brief comment. In Physarum polycephalum both Guttes et al. (1968) and Ryser (1970) were able to follow what they thought to be nucleolar material throughout the various phases of the division. In P. flavicomum (Aldrich, 1969) and Arcyria cinerea this continuity was not noted. It should be pointed out, however, that in $A$. cinerea the difference in electron density between chromosomes and nucleolar material was so slight that it is possible that the material was overlooked. Finally, while both Aldrich (I969) and Ryser (1970) have shown telophase nuclei associated with spindle fibres, the present work is apparently the first report of the persistence of the fibres until so late in telophase in myxomycetes. The fibres were visible even after the virtually complete reconstitution of the nuclear envelope.

This paper is part of a dissertation submitted in partial fulfillment of the requirements of the Ph.D. degree at the University of Texas at Austin under the direction of Dr C. J. Alexopoulos. I thank Dr Alexopoulos for his assistance, Dr H. C. Aldrich for critical review of the manuscript, and Dr W. G. Whaley and the Cell Research Institute for use of the facilities of the Electron Microscope Laboratory. Supported in part by NSF Grant GB68I2X to Dr Alexopoulos and NIH Training Grant 5ToI-00789 to the CRI. SFA Publication no. 76.

\section{REFERENCES}

Aldrich, H. C. (1967). Ultrastructure of meiosis in three species of Physarum. Mycologia 59, 127-148.

AldRICH, H. C. (I969). The ultrastructure of mitosis in myxamoeba and plasmodia of Physarum flavicomum. American Journal of Botany 56 (3), 290-299.

Aldrich, H. C. \& Carroll, G. (I97I). Synaptonemal complexes and meiosis in Didymium iridis. A reinvestigation. Mycologia 63, 308-316.

Aldrich, H. C. \& Mims, C. W. (1970). Synaptonemal complexes and meiosis in myxomycetes. American Journal of Botany 57 (8), 935-94I.

Gray, W. D. \& Alexopoulos, C. J. (1968). Biology of the Myxomycetes, pp. I-288. New York: Ronald Press.

Guttes, S., Guttes, E. \& Ellis, R. A. (1968). Electron microscope study of mitosis in Physarum polycephalum. Journal of Ultrastructural Research 22, 508-529.

McManus, M. A., Roth, L. E. (1968). Ultrastructure of the somatic nuclear division in the plasmodium of the myxomycete Clastoderma debaryanum. Mycologia 60, 426-436.

Mims, C. W. (1969). Capillitial formation in Arcyria cinerea. Mycologia 6r, 784-798.

Ryser, U. (1970). Die Ultrastruktur der Mitosekerne in den Plasmodien von Physarum polycephalum. Zeitschrift für Zellforschung und Microskopische Anatomie 110, 108-130.

SCHUSTER, F. L. (I964). Electron microscope observations on spore formation in the slime mold Didymium nigripes. Journal of Protozoology I1, 207-2 16. 